\title{
The Complex Index System of Water Scarcity Based on the Grey Neural Network Model
}

\author{
Zihao Zheng ${ }^{1, a}$,Shuxiao Wang ${ }^{2, b}$,Jiarui Xing ${ }^{3, c^{*}}$ \\ ${ }^{1}$ School of Mathematical Science, Beijing Normal University, Beijing, China \\ ${ }^{2}$ School of Mathematical Science, Beijing Normal University, Beijing, China \\ ${ }^{3}$ School of Information Science and Technology, Beijing Normal University, Beijing, China \\ a201311181032@mail.bnu.edu.cn, b450739606@qq.com, ‘Xingjiarui1234@163.com
}

Keywords:Water Scarcity; Complex Index System; Grey Neural Network

Abstract.This paper attempts to establish mathematical models to evaluate and predicate water problems in the example of Qingdao.We establish a multi-indexical evaluation system of water resources to access regional water capacity and attempt to analyze the corresponding causes. We use Comprehensive Evaluation Index of Regional Water Resources Carrying Capacity (CW) to reflect the level of water scarcity in the target region; the $\mathrm{CW}$ value is calculated based on six indexes: water resources system index, social system index, economic system index, ecological system index, comprehensive coordination index, social index. Based on the indexical system, we can calculate the future water supply and demand by using prediction model based on principal component analysis and grey neural network respectively. The results show that by 2025, the CW value in Qingdao will first break 1.00 threshold, reaching “over-exploited” level.

\section{Introduction}

It is known to all that water resources are vital to human production and life. Many countries are now in lack of water resources and facing the problem about the pollution of fresh water. According to the United Nations, 1.6 billion people, that is, one quarter of the world's populationexperience water scarcity. In the same time, water use is now growing at twice the rate of population.

Qingdao is one of the cities in Shandong province and we take it as an example. It is a heavily exploited city. Precipitation is the main source of clean water, and Inter-basin water transfer also works, however, as the population of Qingdao grows and economy develops, clean water available in Qingdao cannot meet the demand.

\section{Assumptions}

There will be no wars or serious natural disasters from now on to the year 2025.

There will be no change or a small change in the growth rate of economy.

There will be no change or a small change in the growth rate of population.

The total water resources in our model are available and no waste exists in it.

\section{Evaluation model of water resources based on complex index system}

Construction of complex index system. According to the influencing factors of regional water resources scarcity, we establish a complex index system based on these six aspects: "water resources system index", "social system", "economic system index", "Comprehensive coordination index"and "social indicators".

Model construction.According to thecomprehensive evaluation index system, the expression of regional water resources carrying capacity comprehensive index $(\mathrm{CW})$ is:

$$
\mathrm{CW}=\sqrt[3]{C H I * C C I *\left(\alpha F_{e} I+\beta F_{p} I\right)}
$$


$F_{e} I, F_{p} I$ are economic pressure index and physical pressure index of the water resources in the area, CCI is regional water resources composite system carrying capacity pressure index, CHI is coordination index of the regional water resources composite system, $\alpha, \beta$ are undetermined weights.

CW metrics are as follows:

Table 1.Measure Index and Range of CW

\begin{tabular}{cccccc}
\hline CW & $0.00-0.50$ & $0.50-0.80$ & $0.80-1.00$ & $1.00-1.30$ & $>1.30$ \\
\hline $\begin{array}{c}\text { Bearing } \\
\text { grade }\end{array}$ & $\begin{array}{c}\text { Abundant } \\
\text { water } \\
\text { resources }\end{array}$ & $\begin{array}{c}\text { Slightly } \\
\text { exploited }\end{array}$ & $\begin{array}{c}\text { moderately } \\
\text { exploited }\end{array}$ & $\begin{array}{c}\text { Heavily } \\
\text { exploited }\end{array}$ & $\begin{array}{c}\text { Over- } \\
\text { exploited }\end{array}$ \\
& & & & \\
\hline
\end{tabular}

\section{Regional water resources carrying economic pressure index $F_{e} I$.}

$$
F_{e} I=\frac{F_{e}}{G D P_{c}}
$$

In the expression,

$$
F_{e}=G D P * \frac{W_{s}}{W_{d}}
$$

$F_{e}$ isthe maximum scale economy of regional water resources carrying capacity, $W_{d}$ is the minimum water consumption of the social system and economic system in the region, $W_{s}$ is the maximum amount of available water resources in the area, GDP is the gross domestic product produced when water is $W_{d}$ and $G D P_{c}$ is the gross domestic production.

\section{Regional water resources physical pressure index $F_{p} I$.}

$$
F_{p} I=\frac{F_{p}}{P_{c}}
$$

In the expression,

$$
F_{p}=\frac{G D P}{G D P_{p}}
$$

$F_{p}$ is the largest population of the regional water resources carrying capacity, $G D P_{p}$ is a social development level of per capita GDP threshold and $P_{c}$ is the current population size.

To ensure the sustainable development of society and economy, we should ensure that economies of scale and population size does not exceed the maximum support capacity of water resources in the region,

$$
F_{e} I<1, F_{p} I<1
$$

\section{Carrying pressure index of regional water resources composite system CCI.}

$$
\mathrm{CCI}=\frac{C C P}{C C S}
$$

CCP is the pressure index of water resources system, and CCS is the pressure index of water resources system.

In order to keep the sustainable development of social economy, we should keep that the pressure of water resources social economy system is not more than the support capacity, that is, the carrying pressure index $\mathrm{CCI}<1$. In order to make the weight of each index in the table can be expressed in the composite system, in the calculation of the CCI, this study uses entropy method to determine the weights of the indexes in the composite system, that is, according to the objective social, economic, ecological and water quality status of the original information carrying amount to determine the index weight.

The greater the information content of entropy, the smaller theuncertainty is, the smaller the entropy is. On the other hand, the smaller information content, the greater the uncertainty is, the 
greater the entropy is. By means of index variation analysis, the relationship among different indexes is analyzed, and the error caused by subjective factors is avoided.

Water resources, social, economic and ecological complex system coordination index CHI. For water resources, social, economic and ecological complex system, the degree of order of each subsystem is

$$
\mathrm{u}_{\mathrm{k}}\left(\mathrm{e}_{\mathrm{k}}\right), \mathrm{k}=1,2,3,4
$$

$\overline{u_{k}\left(e_{k}\right)}$ is the average value of each index area for many years.

At the time of $\mathrm{T}$, the coordination index of complex system is

$$
\begin{aligned}
& \text { CHI }=\theta \sqrt[4]{\prod_{k=1}^{4} u_{k}\left(e_{k}\right)-\overline{u_{k}\left(e_{k}\right)}} \\
& \theta=\frac{\min \left[u_{k}\left(e_{k}\right)-\overline{u_{k}\left(e_{k}\right)}\right]}{\left|\prod_{k=1}^{4} u_{k}\left(e_{k}\right)-\overline{u_{k}\left(e_{k}\right)}\right|}
\end{aligned}
$$

The greater the value of coordination index CHI, the higher degree of coordinated development of regional society, economy, ecology and water resources complex system.

\section{Model calculation}

Water shortage degree of Qingdao City. According to the requirements of task2, the degree of water resources in Qingdao city is overloaded heavily, in accordance with the requirements of the subject. According to CW algorithm, we collect the data of the Qingdao City, and get the CW value of Qingdao city in 2015 was 0.856, between 0.80-1.00.

Explanation of water resources shortage in Qingdao. Water resources in Qingdao city are in the light of scarcity, the specific reasons can be explained from the following three aspects:

(1) Physical scarcity. The amount of water resources that can be used in a region of Qingdao city cannot meet the economic, social and ecological water demand. The value of $\boldsymbol{F}_{\boldsymbol{p}} \boldsymbol{I}$ in Qingdao city is 0.785 , which is $176 \%$ of the world's average level. Therefore, the total amount of water resources in Qingdao is in short supply.

(2) Economic scarcity. At the same time, the value of Qingdao's economic pressure index $\boldsymbol{F}_{\boldsymbol{e}} \boldsymbol{I}$ is 0.873, which did not exceed the world average. This means that Qingdao city does not have adequate water supply facilities and water harvesting measures.

(3) Systematic scarcity. Qingdao water resources, social, economic and ecological composite system coordination index CHI 0.93, has just reached the world average.

\section{Forecasting model of water resources shortage}

In order to predict the degree of scarcity of water resources in Qingdao city in 15 years, we use the following two models to forecast the demand and supply of water resources in Qingdao city.

Prediction model of water resources carrying capacity of water resources based on principal component analysis and grey neural network.

Simplified principal component analysis of complex index system

(1) Simplification of complex index system.By simplifying the complex index system, the social and economic factors that affect the carrying capacity of water resources can be summed up as 3 aspects of quantitative indicators, namely, water resources system itself, social development indicators, economic indicators.

(2) The principal component regression model. Principal component analysis (PCA) is the idea of dimensionality reduction, multiple index into several comprehensive indexes of multivariate statistical methods in little loss of information of the premise, to simplify the complexity of the problem and catch the main contradiction. In this paper, the data of 1997-2013 is used to extract the principal components from the above 17 indexes which 
influence the water demand. Assuming that they are using $\mathrm{x} \_1, \mathrm{x} \_2, \ldots, \mathrm{x} \_13$ said, we can get the variable matrix by standardization $\mathrm{T}$ :

$$
\left[\begin{array}{ccc}
\mathrm{t}_{11} & \cdots & \mathrm{t}_{1 \mathrm{p}} \\
\vdots & \ddots & \vdots \\
\mathrm{t}_{\mathrm{q} 1} & \cdots & \mathrm{t}_{\mathrm{qp}}
\end{array}\right] \quad \mathrm{p}=1,2, \ldots, 13 ; \mathrm{q}=1,2, \ldots 17 .
$$

We establish the principal component model by using the normalized variable matrix

$$
F_{i}=a_{1, i} t_{1}+a_{2, i} t_{2}+\cdots+a_{13, i} t_{13}
$$

$F_{1}, F_{2}, F_{m}$ are the principal components, $a_{1, i}, a_{2, i}, \ldots, a_{13, i}$ are the characteristic values of the correlation coefficient matrix of the original index data, satisfying:

$$
\sum_{k=1}^{13} a_{k, 1}^{2}=1
$$

We use SPSS statistical software to analyze the data, the variable index matrix related to the three characteristics of value $\lambda_{1}, \lambda_{2}, \lambda_{3}$ together accounted for approximately is $89.62 \%$, so three principal components can already to some degree on behalf of the original variable information.

Weight and contribution rate of principal component index:

Table 2.Results of Principal Component Analysis(PCA)

\begin{tabular}{ccccccc}
\hline & \multicolumn{3}{c}{ Initial eigenvalue } & \multicolumn{3}{c}{ Extraction square } \\
\cline { 2 - 7 } component & total & $\begin{array}{c}\text { Variable } \\
\text { contribution }\end{array}$ & $\begin{array}{c}\text { Cumulative } \\
\text { contribution }\end{array}$ & total & $\begin{array}{c}\text { Variable } \\
\text { contribution }\end{array}$ & $\begin{array}{c}\text { Cumulative } \\
\text { contribution }\end{array}$ \\
\hline 1 & 6.891 & 53.011 & 53.011 & 6.891 & 53.011 & 53.011 \\
2 & 2.427 & 18.668 & 71.679 & 2.427 & 18.668 & 71.679 \\
3 & 1.683 & 12.945 & 89.624 & 1.683 & 12.945 & 84.624 \\
$\ldots$ & $\ldots$ & $\ldots$ & $\ldots$ & $\ldots$ & $\ldots$ & $\ldots$ \\
\hline
\end{tabular}

Principal component regression model is

$$
\mathrm{Y}=1.099 * 10^{-15}+0.854 F_{1}+0.323 F_{2}-0.283 F_{3}
$$

Equation simulation regression results show that the 3 principal component regression coefficient of the modified sample coefficient is 0.872 , the F test statistic is 48.491 , the DW statistic is 1.863 , so the t test is qualified.The corrected samples can be checked by the test of the coefficient of determination and F statistics, the regression equation is fitted well on the whole, and the influence of the regression coefficient is relatively significant.

\section{Grey neural network forecasting model.}

(1) Grey prediction GM $(\mathbf{1}, \mathbf{N})$ model. Grey system theory is mainly based on the formation and development of known information, to extract valuable information, to describe and effectively monitor the behavior and evolution of the system. Grey GM $(1, \mathrm{~N})$ model is one of the main contents of grey system theory.The model is based on discrete series to establish approximate continuous differential equations, reflecting the influence of the first derivative of $\mathrm{n}-1$ variables on one variable.

Set $x^{(0)}$ as the original sequence

$$
x^{(0)}=\left\{x_{(1)}^{(0)}, x_{(2)}^{(0)}, x_{(3)}^{(0)}, \ldots, x_{(n)}^{(0)}\right\}
$$

Note $x^{(1)}$ is the generation of sequences 


$$
\begin{aligned}
& x^{(0)}=\left\{x_{(1)}^{(1)}, x_{(2)}^{(1)}, x_{(3)}^{(1)}, \ldots, x_{(n)}^{(1)}\right\} \\
& x_{(k)}^{(1)}=\sum_{i=1}^{k} x_{(i)}^{(0)}
\end{aligned}
$$

Set

$X_{1}^{(0)}=\left(x_{1}^{(0)}(1), x_{1}^{(0)}(2), \ldots, x_{1}^{(0)}(n)\right)$

as the system characteristic sequence, and

$X_{k}^{(0)}=\left(x_{k}^{(0)}(1), x_{k}^{(0)}(2), \ldots, x_{k}^{(0)}(n)\right), \mathrm{k}=1,2, \ldots, \mathrm{N}$

as the sequence of related factors. We call

$x_{1}^{(0)}(k)+\mathrm{a} Z_{1}^{(1)}=\sum_{i=2}^{N} b_{i} x_{i}^{(1)}(k)$

the GM $(1, N)$ model and

$Z_{1}^{(1)}=\frac{1}{2}\left[X_{1}^{(1)}(k)+X_{1}^{(0)}(k-1)\right]$

The grey forecasting model is as follows:

\section{(a)Establisha differential equation}

$\frac{d x_{1}^{(1)}}{d t}+a x_{1}^{(1)}=\sum_{i=2}^{N} b_{i} x_{i}^{(1)}$

The parameters of the equation are classified as

$\hat{a}=\left[a, b_{1}, b_{2}, \ldots, b_{N}\right]^{T}$

$b_{i} x_{i}^{(1)}(k)$ is the driving direction and $b_{i}$ is the driving factor.

(b) Using the least square method to get the parameter list

Set

$\mathrm{B}=\left[\begin{array}{ccc}-Z_{1}^{(1)}(2) & \cdots & x_{N}^{(1)}(2) \\ \vdots & \ddots & \vdots \\ -Z_{1}^{(1)}(n) & \cdots & x_{N}^{(1)}(n)\end{array}\right]$

$\mathrm{Y}=\left[x_{1}^{(0)}(2), x_{1}^{(0)}(3), \ldots, x_{1}^{(0)}(n)\right]^{T}$

and

$\hat{a}=\left[a, b_{1}, b_{2}, \ldots b_{N}\right]^{T}=\left(B^{T} B\right)^{-1} B^{T} Y$

(c) Based on the above analysis, we obtain the approximate time response equation of GM $(1, N)$

$$
\begin{aligned}
& \hat{x}_{1}^{(1)}(k+1)=\left[x_{1}^{(1)}(0)-\frac{1}{a} \sum_{i=2}^{N} b_{i-1} x_{i}^{1}(k+1) e^{-a k}+\frac{1}{a} \sum_{i=2}^{N} b_{i-1} x_{i}^{(1)}(k+1)\right] \\
& \hat{x}_{1}^{(0)}(k+1)=\hat{x}_{1}^{(1)}(k+1)-\hat{x}_{1}^{(1)}(k)
\end{aligned}
$$

Among them, $x_{1}^{(1)}(0)$ is $x_{1}^{(1)}(1)$

(2) Grey neural network forecasting model. Grey neural network model is a kind of combination forecasting model. The forecasting system combines the grey system theory and 
artificial neural network, which aims to combine the advantages of the gray theory with the characteristics of the neural network to weaken the volatility and the randomness of the data, improving the accuracy of neural network fusion.

The gray neural network forecasting model is as follows: we set time series

$$
\left\{X_{(i)}^{(0)}\right\}(\mathrm{i}=1,2, \ldots, \mathrm{n})
$$

We use GM (1, N) model to calculate the value of data reduction

$$
\hat{x}_{(i)}^{(0)}(i=1,2, \ldots, n)
$$

We set the moment $L$ residuals $e_{(L)}^{(0)}$

$$
\mathrm{e}_{(\mathrm{L})}^{(0)}=\mathrm{x}_{(\mathrm{L})}^{(0)}-\hat{\mathrm{x}}_{(\mathrm{L})}^{(0)}
$$

(a) Establish the BP network model of the residual series

Let $e_{(L)}^{(0)}$ as residual series. If the prediction order is $\mathrm{S}$, that is, using $e_{(i-1)}^{(0)}, e_{(i-2)}^{(0)}, \ldots, e_{(i-s)}^{(0)}$ as the training samples of BP neural network, using them to predict future time value and use them to predict future values.First we set $e_{(i-1)}^{(0)}, e_{(i-2)}^{(0)}, \ldots, e_{(i-s)}^{(0)}$ as the input sample of network training and the value of $\mathrm{e}_{(\mathrm{i})}^{(0)}$ as output

(b) Determine the new predictive value of $\left\{e_{(L)}^{(0)}\right\}$

$$
\hat{x}_{(i, 1)}^{0}=\hat{x}_{(i)}^{0}+\hat{e}_{(1)}^{0}
$$

and $\hat{x}_{(i, 1)}^{0}$ is the prediction sequence grey artificial neural network model.

Model calculation. First step, based on the grey prediction model, we establish the data series of the annual water consumption of Qingdao city. The GM $(1,7)$ grey prediction model of water resources in Qingdao is obtained by using the analysis software to fit the data.

$$
\begin{aligned}
& \hat{x}_{1}^{(1)}(k+1)=\left[x_{1}^{(1)}(0)-\frac{1}{a} \sum_{i=2}^{7} b_{i-1} x_{i}^{(1)}(k+1) e^{-a k}+\frac{1}{a} \sum_{i=2}^{7} b_{i-1} x_{i}^{(1)}(k+1)\right] \\
& \quad \mathrm{a}=1.3686, b_{2}=1445.3, b_{3}=3273, b_{4}=188.1, b_{5}=0.9, b_{6}=-127.8, b_{7}=42.5
\end{aligned}
$$

\begin{tabular}{|c|c|c|c|c|c|c|c|c|c|}
\hline Year & 2014 & 2015 & 2016 & 2017 & 2018 & 2019 & 2020 & 2021 & 2022 \\
\hline water & 1214 & 1256 & 1289 & 1299 & 1303 & 1315 & 1328 & 1330 & 1342 \\
\hline $\begin{array}{c}\text { demand } \\
\text { ( ton ) }\end{array}$ & 7 & 9 & 1 & 3 & 5 & 7 & 0 & 2 & 4 \\
\hline \multicolumn{10}{|c|}{ Table 4.The Prediction of Water Demand in Qingdao from 2022 to 2030} \\
\hline Year & 2023 & 2024 & 2025 & 2026 & 2027 & 2028 & 2029 & 2030 & \\
\hline water & 1354 & 1366 & 1369 & 1371 & 1373 & 1382 & 1387 & 1400 & \\
\hline $\begin{array}{c}\text { demand } \\
\text { (ton ) }\end{array}$ & 6 & 8 & 0 & 2 & 4 & 6 & 8 & 0 & \\
\hline
\end{tabular}

Second step, by predicting the annual water consumption in the model, we carry out the model back to test, and find out the residual series, including 15 years of annual water consumption forecasting residual series.

We get the forecast of water demand of Qingdao in 2014-2030

Table 3. The Prediction of Water Demand in Qingdao from 2014 to 2022

15 years later, in 2030, the water demand of Qingdao city will be 14000.674 tons 


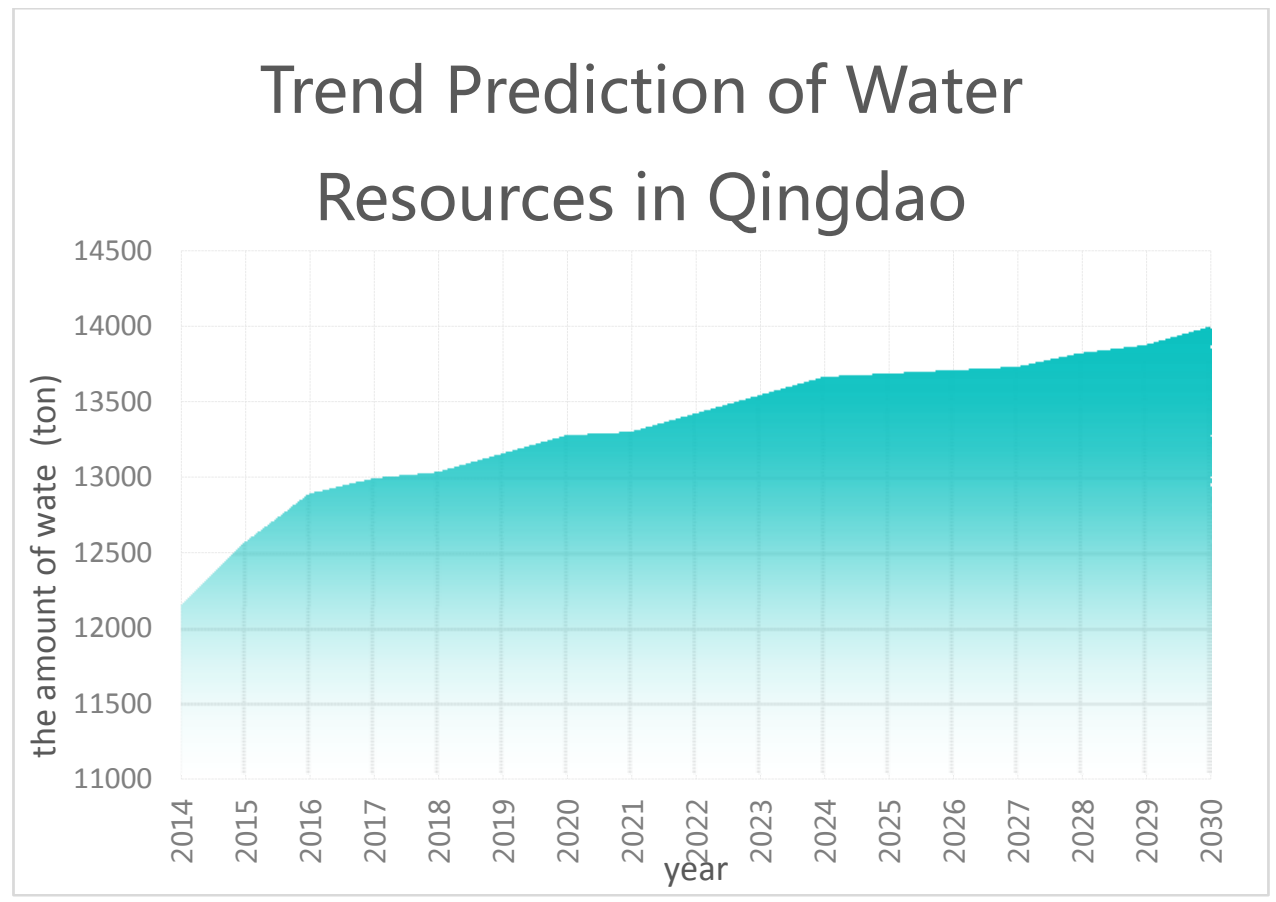

Figure 1. Trend Prediction of Water Resources in Qingdao

\section{Conclusion}

The Value of CW in Qingdao predicting. Combining the two models, we get the CW value of the water resources in Qingdao city from 2015 to 2030.

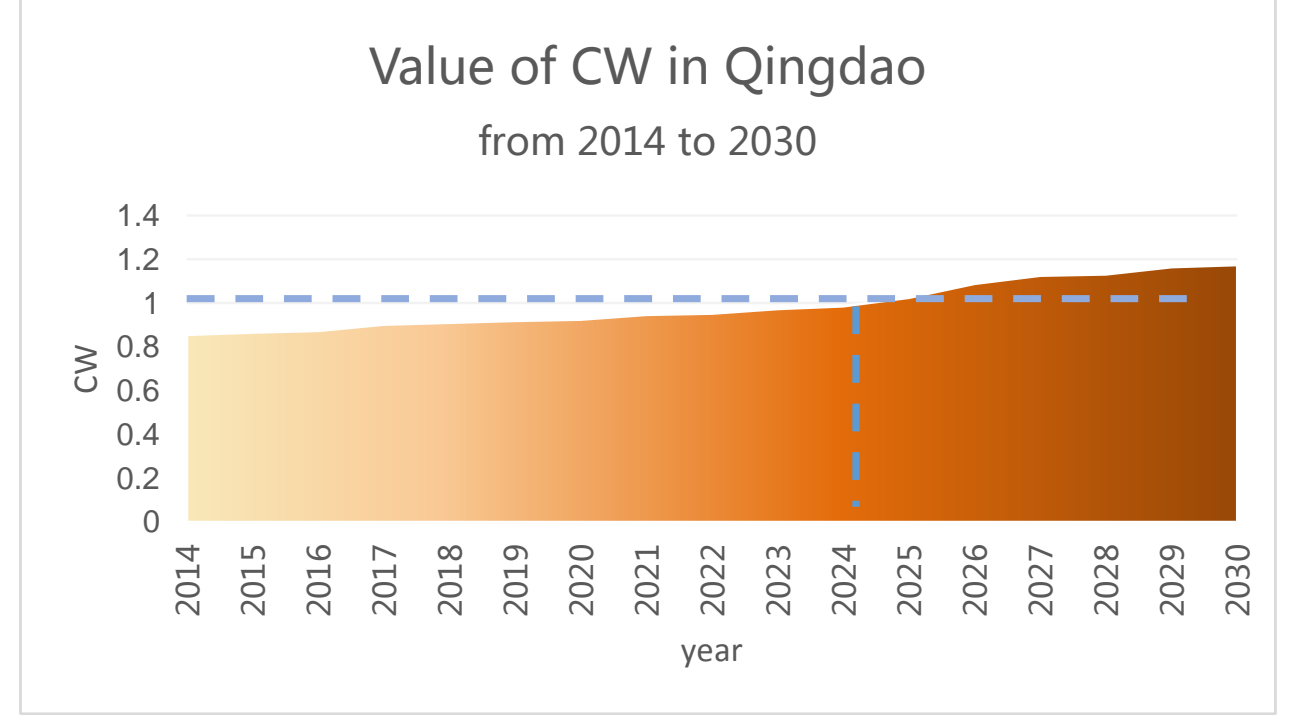

Figure 2. The predicting Value of CW in Qingdao from 2014 to 2030

We find that until 2025, Qingdao's CW value is below 1, while in 2025 Qingdao's CW value for the first time exceeded 1 and 1.025 means that Qingdao's water resources will be over-exploitedin 2025.

\section{Model examination and sensitivity analysis}

\section{Model examination}

Model examination of complex index system. In order to verify whether the model is reasonable to measure the degree of water shortage in a region,we use the complex index system model to calculate the water shortage degree index CW in China and compare it with the distribution of water shortage situation in China announced by the World Health Organization. 


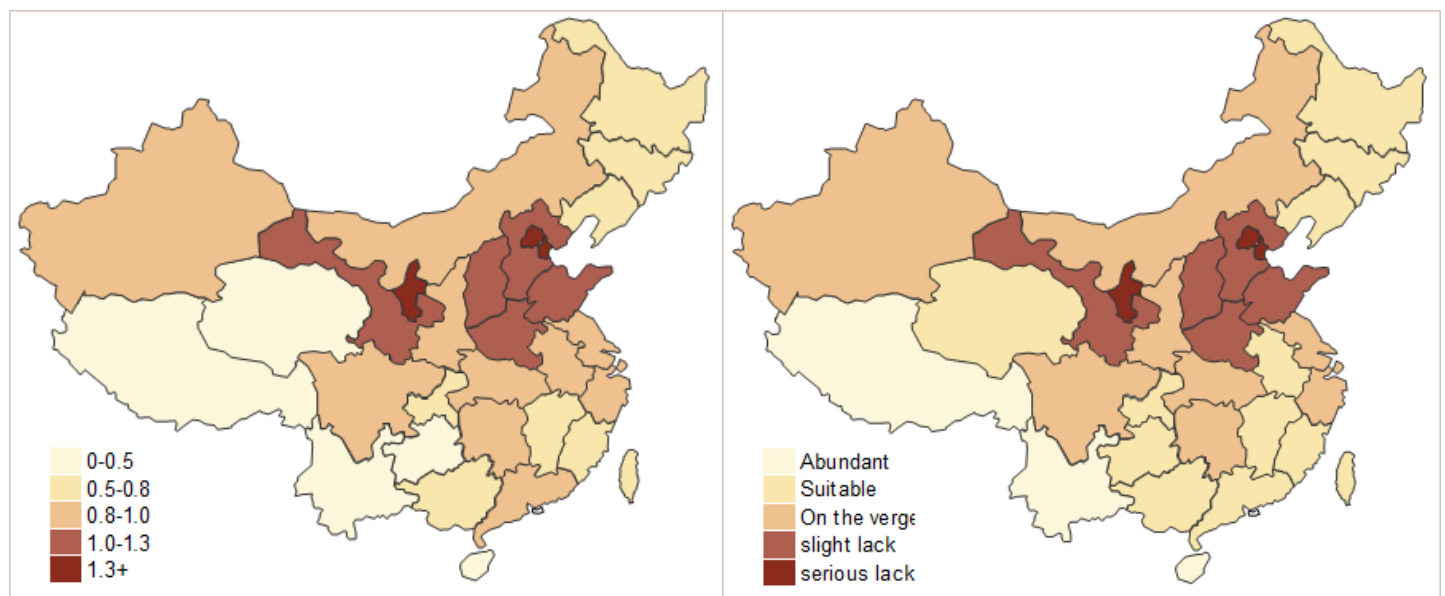

Figure 3. The Distribution Map of Water Scarcity based on Prediction and WHO

We can find the left one (according to CW shortage degree of water resources distribution map) and the right one (the official announcement of the shortage degree of water resources distribution map) is generally consistent except for Qinghai Province, Guangdong Province and Guizhou Province. This shows that the model checking effect is good.

Model examination of Grey neural network forecasting model. According to the grey system theory to determine the accuracy of the model test method, this paper choose the post test method. The mean and variance of the original sequence $\boldsymbol{x}^{(\mathbf{0})}$ are

$$
\begin{aligned}
& \bar{x}=\frac{2}{n} \sum_{k=1}^{n} x_{(k)}^{(0)} \\
& S_{1}^{2}=\frac{1}{n} \sum_{k=1}^{n}\left(x_{(k)}^{(0)}-\bar{x}\right)^{2}
\end{aligned}
$$

Mean and variance of residual are

$$
\begin{aligned}
& \bar{\varepsilon}=\frac{1}{n} \sum_{k=1}^{n} \varepsilon_{(k)}^{(0)} \\
& S_{2}^{2}=\frac{1}{n} \sum_{k=1}^{n}\left(\varepsilon_{(k)}^{(0)}-\bar{\varepsilon}\right)^{2}
\end{aligned}
$$

And we note that

$$
\mathrm{C}=\frac{S_{2}}{S_{1}}
$$

as the mean variance ratio.

For a given $C_{0}>0$, when $C<C_{0}$, the model is the mean square deviation ratio of the qualified model,

$$
\mathrm{P}=\mathrm{P}\left(\left|\varepsilon_{(k)}^{(0)}-\bar{\varepsilon}\right|<0.6745 S_{1}\right)
$$

is called small error probability. For a given $P_{0}>0$, whenP $>P_{0}$, the model is a small error probability model.

Through the calculation of the residual series, the small error probability of the grey prediction model is 0.8636 , and the mean square error ratio is 0.4430 . According to the accuracy test grade reference table, the small error probability and the standard deviation ratio of the model are all in the qualified range. 
Table 5. The standard of model examination of Grey neural network forecasting model

\begin{tabular}{ccc}
\hline Precision grade & Mean variance ratioC $_{0}$ & Small errorP $_{0}$ \\
\hline good & $<0.35$ & $>0.95$ \\
qualified & $<0.50$ & $>0.80$ \\
Barely qualified & $<0.65$ & $>0.70$ \\
unqualified & $>0.65$ & $<0.7$ \\
\hline
\end{tabular}

\section{Strengths and Weaknesses}

\section{Strengths}

(1) We establish a multi-indexical evaluation system of water resources to access regional water capacity and attempt to analyze the corresponding causes.

(2) We calculate the future water supply and demand by using auto regressive model in time series and prediction model based on principal component analysis and grey neural network respectively.

\section{Weaknesses}

(1) We don't establish a model to calcite the future water supply and demand in agriculture and industry for the lack of data.

(2) We don’t analysis more about the inter-basin water transfer for the lack of data

\section{Acknowledgements}

This work is supported by Beijing Normal University.

\section{References}

[1] Rijiberman J, van de VenFrans H M. Different approaches to assessment of design and management of sustainable urban water system[J]. Environment Impact Assessment Review, 2000, 129(3): 333-345.

[2] Daily G C, Ehrlich P R. Population, sustainability, and Earth's carrying capacity[J]. BioScience, 1992, 42(10): 761-771.

[3] Daily G C, Ehrlich P R. Socioeconomic equity, sustainability, and Earth's carrying capacity[J]. Ecological Applications, 1996: 991-1001.

[4] [WCED] World Commission on Environment and Development. World Commission on Environment and Development: Our Common Future[J]. 1987.

[5] Zhang B, Govindaraju R S. Prediction of watershed runoff using Bayesian concepts and modular neural networks[J]. Water Resources Research, 2000, 36(3): 753-762.

[6] Marina C, Afredo S. Forecasting river flow rate during low--flow period using neural network[J]. Water resources research, 1999, 35(11): 3547-3552.

[7] Wurbs R A. Reservoir-system simulation and optimization models[J]. Journal of water resources planning and management, 1993, 119(4): 455-472.

[8] Taghavi et al.Optimal control of ground-water quality management: nonlinear programming approach[J].Journal of water resources planning and management

[9] Takyi A K, Lence B J. Surface water quality management using a multiple - realization chance constraint method[J]. Water Resources Research, 1999, 35(5): 1657-1670. 